\title{
Finite Element Software for Rubber Products Design
}

\author{
D. HURI
}

Department of Mechanical Engineering, Faculty of Engineering, University of Debrecen, huri.david@eng.unideb.hu

Abstract: Automotive rubber products are subjected to large deformations during working conditions, they often contact with other parts and they show highly nonlinear material behavior. Using finite element software for complex analysis of rubber parts can be a good way, although it has to contain special modules. Different types of rubber materials require the curve fitting possibility and the wide range choice of the material models. It is also important to be able to describe the viscoelastic property and the hysteresis. The remeshing possibility can be a useful tool for large deformation and the working circumstances require the contact and self contact ability as well. This article compares some types of the finite element software available on the market based on the above mentioned features.

\section{Introduction}

Finite element simulation of rubber parts is still a demanding task for engineers thanks to the combined effect of several factors. The first one is the elastic modulus of the rubber which depends on the rubber recipe, the shape of the rubber and the size of the deformation as well. The rubber shows nonlinear behavior, therefore the software has to have nonlinear solver ability. While the producers handle the rubber recipe as an industrial secret the mechanical properties have to be determined by laboratory measurements. In most cases the rubber behaves as an elastic, isotropic and nearly incompressible material and it can undergo large deformation. The application of hyperelastic material law is recommended with the above given conditions. In certain cases the viscoelastic behavior of rubber has to be taken into consideration. Such viscoelastic properties are the creep, the stress relaxation and the hysteresis.

Further aim is to develop shape optimization method for technical rubber products and this led to the study of FEM based calculation processes. The accurate simulation of the material response of the rubber part is a basic requirement. Due to the large number of finite element model variations in shape optimization the applicated finite element software is expected to be programmable.

\section{Special purpose finite element codes developed for the finite element analysis of rubbers}

Basically the finite element software can be divided into two main groups, general purpose or special purpose. The advantage of systems used for general purpose that they can be formed for any special task. They have a disadvantage on the market that the process of meshing must be done manually which 
takes too much time and sometimes it cannot follow the geometrical modifications. The way until the solution is sometimes complicated because of the high number of properties that is why the time cannot be planned properly. It is needed to have a person who has experience in this finite element field to get reliable results.

The special purpose code has the advantage that the preparation of the finite element model can be handled less time consumingly and the running time can be reduced as well. The disadvantages of that kind of programs are the limited application for problem solving, while only predefined geometries can be analyzed.

FED12 by Hexagon Ltd. is a special purpose finite element software and it is suitable for the determination of the force-displacement curve of cylindrical rubber spring with bore or without bore till 50\% compression.

A finite element code written in FORTRAN has been developed for the analysis of nearly incompressible axially symmetric rubber parts [1,2]. The developed finite element code and the support vector regression (SVR) method were used for the optimization of the shape of axi-symmetric rubber bumpers $[3,4]$. It has to be noted that these programs are not able to simulate complex and coupled problems.

\section{General purpose finite element packages for the finite element analysis of rubbers}

The finite element packages including nonlinear solver and hyperelastic material law can be applied for the design of rubber parts. There are several software packages available with the above mentioned properties. Including but not limited to the following commercial software is suitable for the finite element investigations of rubbers: Abaqus, Adina, Algor, Amps, Ansys, Autodesk Simulation Mechanical, Caefem, Comsol Multiphysics, Feap, Femap, Keycreator Analysis, Ls-Dyna, Lusas Analyst, Midasnfx, Msc Marc, Nisa Mechanical, PAK-S, Radioss (Altair), Samcef, SimScale, Solidworks Simulation, Solvia, Strand 7. There are also some pieces of open source finite element software, like: CalculiX, CodeAster, FEBio with Pre View, Tochnog.

I have searched for some articles which used ABAQUS for analyzing materials made of rubber. Some articles are about the analysis of seals [5-8]. According to [9] an axi-symmetric finite element model of an air spring was analyzed to design its target vertical stiffness. The bellows were simulated by the reinforced surface element. The compressed gas in the cavity of the air spring was represented by hydrostatic fluid element. The target stiffness is obtained by modifying the valid area of the cross section. A differential evolution algorithm based approach is developed in [10] to optimize the rubber bushing through integrating a finite element code running in batch mode to compute the objective function values for each generation. Rubber product fatigue life prediction was investigated in [11,12]. Through the finite element simulation the fatigue damage dangerous positions were obtained. Mesh locking problem of incompressible materials occured in case of large deformations was analyzed in [13]. Local stress increasing can be seen in the locked elements. For this case the literature recommends a special meshing process and finer mesh size and due to this process the distortion of elements can be reduced and as a result the solution will be better and there will be a reliable analysis running. 
In many cases ANSYS is used for process analyzing [14-19]. The paper [14] deals with modeling and simulation of the static and dynamic behavior of radial tires for vehicles. The simulation results were equal with the imprint of the tire on the road surface. In [15-17] different sealing products were investigated. An approach for analyzing and optimizing sealing mechanism of ball valve made of nitrile butadiene rubber (NBR) with finite element method was presented in [16]. Different alternatives for rubber bushing was examined to get better model to satisfy endurance limit in [18]. The conclusion was that the higher value of strain was a prime reason for failure of the base model. As hardness increases, strain at the taper portion goes on reducing and hence the fatigue life of component increasing which is verified by the endurance test.

The 'White Paper' published by MSC software corporation shares some experience about measurement methods and expert's reports regarding the analysis of elastomer materials in [20]. The practical use of MSC software can be found in some other publications [21-25]. During the analysis of rubber, the deformation can be so large that the mesh used to model the product may become highly distorted, and the analysis cannot go any further without using some special techniques. Remeshing or rezoning in Marc is a useful feature to overcome these difficulties [21]. In order to model wear that is larger than the elements of the FE mesh, a wear simulation procedure was developed using global remeshing in [22]. Automotive door sealing products and its cross section were investigated in [23,24]. Comparison between Back Propagation (BP) neural network and the Kriging surrogate model was made in [24]. BP neural network which performs better and more efficient in this automotive design optimization field is applied for extracting nonlinear mapping between five cross- section parameters and compression load, which were parallelly optimized by Genetic Algorithm (GA) and its efficiency and accuracy are compared with another evolutionary algorithm of Particle Swarm Optimization (PSO).

Results of an extensive series of simulation tests to identify the mechanical characteristics of an innovative isolation device known as the Roll-N-Cage (RNC) isolator using ADINA finite element software was presented in [26].

Rubber bumpers were investigated using Femap [27, 28]. Finite element calculation based on optimization methods were investigated from the point of view of time demand. A solution of a contact problem including friction for large displacements and deformations was analyzed where a rubber bumper applied in air-springs is investigated by determining the nonlinear load-displacement curve.

\section{Software suitable for the determination of rubber material constants}

For the description of the hyperelastic behavior several material models are used, e.g. Mooney-Rivlin, Ogden or Yeoh, etc. Uniaxial tensile and compression, biaxial tensile and shear tests are indispensable to be able to determine the special material parameters for each material model. The material parameters can be determined by using curve fitting procedure based on the resulted stress-strain curves. Some of the general purpose finite element packages include the curve fitting possibilities, e.g. 
Ansys, Adina, MSC Marc, Abaqus. However, HyperFit and MCalibration developed especially for only curve fitting are available as well.

HyperFit is a software package developed under Matlab for simplifying the choice of an hyperelastic model and the determination of its constants for a particular material. An example for the application and usage is presented and discussed in [29].

Experimental data from uniaxial tensile tests were used in order to calibrate hyperelastic constitutive models of the material behavior. The constitutive model parameters were evaluated in Abaqus. The 3D model simulation results of a dumbbell shaped rubber specimen under uniaxial tension showed good correspondence with the experimental data [30]. A bulge test was set up to carry out equibiaxial tests in [31]. The bulge test has been coupled with optical devices allowing measurement in real time of the stress and elongation levels of the specimen. Abaqus finite element analyses of the tests agreed properly with the experimental results.

A theoretical background on the computer aided engineering (CAE) based application for the identification and verification of hyperelastic material parameters and an overview of its functionality are presented in [32]. An application developed using Visual Basic.NET language implemented a twoway interaction with Ansys. The ranking of hyperelastic models is constructed according to the models efficiency, which is estimated using fitting quality criteria. Ansys users proved that the Shore hardness of elastomers can be used as a reference for the material constants of the two-term Mooney-Rivlin material model [33]. Experiences showed this reference is not consistent for all grades and types of hyperelastic materials, thus it is advisable to carry out a tensile test at least.

Viscoelastic properties of an ethylene propylene diene rubber (EPDM) were determined by dynamic mechanical thermal analysis (DMTA) measurements. A 15-term Maxwell-model was created to describe the time-dependent material behavior. A rolling test was simulated with the MSC Marc finite element software using the evaluated viscoelastic material properties [34].

\section{Results}

The above mentioned analyses pointed that the software used for complex analysis of rubber parts has to contain special modules. Different types of rubber materials require the curve fitting possibility and the wide range of the material models. It is also important to be able to describe the viscoelastic property and the hysteresis. The remeshing possibility can be a useful tool for large deformation and the working circumstances require the contact and self contact ability as well. Shape optimization problems require the series of finite element models which is time consuming, therefore programming possibility of the software is advantageous [13, 35-38].

In Table 1 the compliance of software based on the requirements are listed. It can be seen that most of the software offers good material choice, furthermore Femap, MSC Marc, Abaqus and Ansys contain the programming possibilities and self contact. The curve fitting and remeshing tools are included only in MSC Marc, Abaqus and Ansys. 


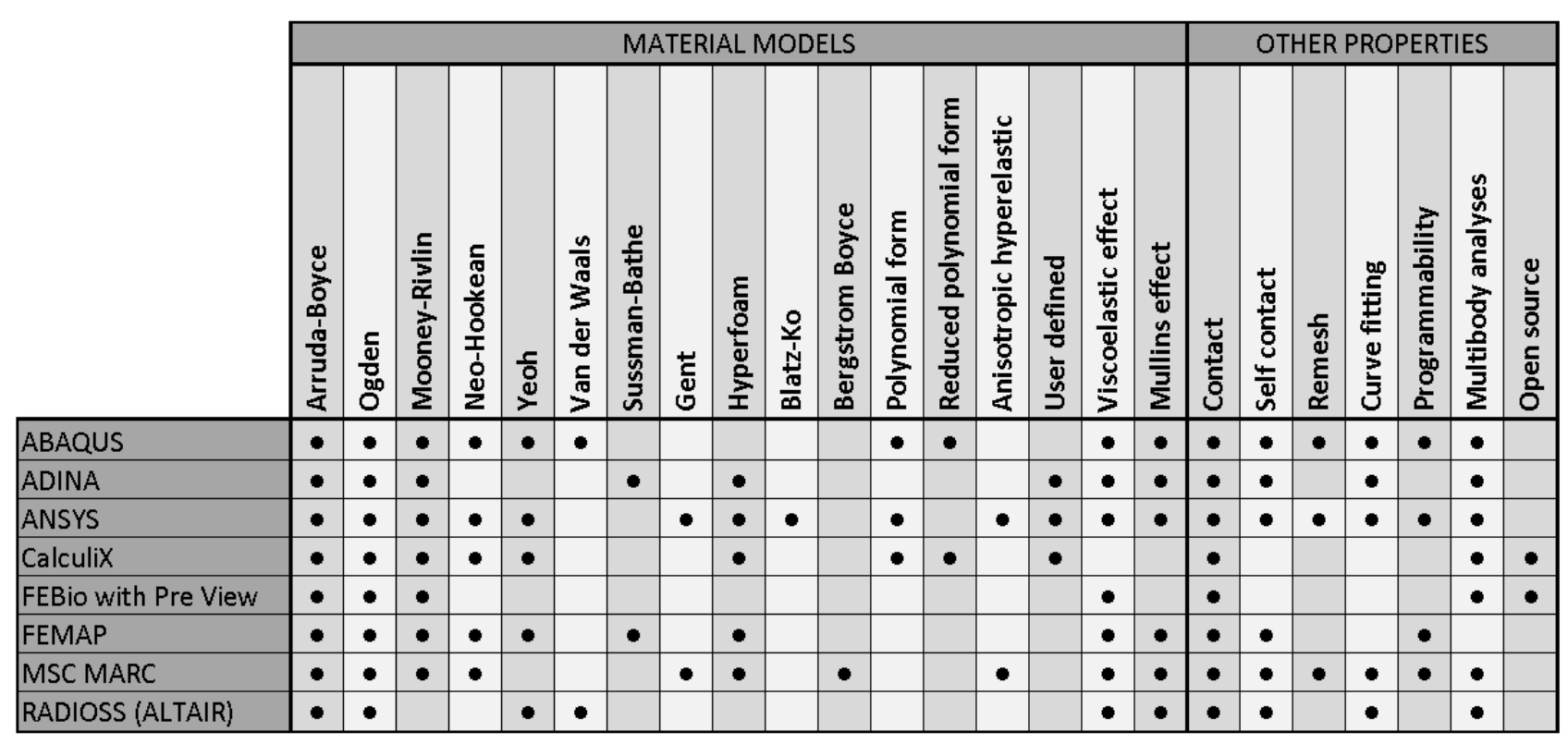

Table 1. Comparison of finite element software based on special requirements for rubber analysis

\section{Conclusions}

Special purpose finite element software would have several advantages but they are not known because of their restricted usability. The research presented the barriers of the finite element softwares for rubber product design available on the market. At the Faculty of Engineering of University of Debrecen Ansys and Femap finite element programs are available. Each of the two software can be used for my future researches as they have the wide variety of the material models, self contact and programmability abilities. If we would like to use the curve fitting and remeshing possibilities, it is advisable to choose the Ansys. It is noted that Abaqus, Ansys and MSC Marc seemed to be used widely for rubber products design according to the examined articles.

\section{Acknowledgement}

THE PUBLICATION IS PARTLY SUPPORTED BY THE EFOP-3.6.1-16-2016-00022 PROJECT. THE PROJECT IS CO-FINANCED BY THE EUROPEAN UNION AND THE EUROPEAN SOCIAL FUND.

$\Rightarrow$

" EXCELLENCE PROGRAM OF THE MINISTRY OF HUMAN CAPACITIES"

\section{References}

[1] T. Mankovits, T. Szabó, Finite element analysis of rubber bumper used in air-springs, Procedia Engineering, 2012 
[2] T. Mankovits, T. Szabó, Nemlineáris VEM program gyakorlati alkalmazása gumialkatrészekre, Multidiszciplináris tudományok: a Miskolci Egyetem közleménye 2, 2012

[3] T. Mankovits, T. Szabó, I. Kocsis, I. Páczelt, Optimization of the shape of axi-symmetric rubber bumpers, Stroj Vestnik - Journal of Mechanical Engineering, 2014

[4] T. Mankovits, I. Kocsis, T. Portik, T. Szabó, I. Páczelt, Shape design of rubber part using FEM, International Review Of Applied Sciences And Engineering, 2013

[5] W. Le, Y. Wang, D. Miao, Finite Element Analysis on Rubber Sealing Ring of the Rotary Liner Hanger Bearing, International Conference on Modelling, Simulation and Applied Mathematics, 2015

[6] I.l J. Abubakar, P. Myler, E. Zhou, Constitutive Modelling of Elastomeric Seal Material under Compressive Loading, Modeling and Numerical Simulation of Material Science, 2016

[7] C. Oliver, L. Jézéquel, S. Besset, F. V. Herpe, Z. Abbadi, Door And Window Seal Impact On Acoustic And Vibrational Behavior Of Aerodynamic Noise, ICSV22, 2015

[8] V. Sivakumar, R. Palaninathan, FE Analysis of Contact Pressure Prediction on O-Rings Used in Solid Rocket Booster Segment Joints, International Journal of Science and Engineering Applications, 2012

[9] H. Li, K. Guo, S. Chen, W. Wang, F. Cong, Design of Stiffness for Air Spring Based on ABAQUS, Hindawi - Mathematical Problems in Engineering, 2013

[10] N. Kaya, Shape optimization of rubber bushing using differential evolution algorithm, Hindawi - The Scientific World Journal, 2014

[11] G. Feng, W. Shi, H. Zhang, Q. Zu, T. Teng, Z. Wu, Research on the Fatigue Life Prediction Method of Thrust Rod, Hindawi - Mathematical Problems in Engineering, 2016

[12] W. V. Mars, D. Ostberg, Fatigue Damage Analysis of an Elastomeric Tank Track Component, SIMULIA Community Conference, 2012

[13] Dessault Systémes: ABAQUS 6.10, Getting Started with Abaqus, Interactive Edition, 2010

[14] T. Giurgiu, F. Ciortan, C. Pupaza, Static and Transient Analysis of Radial Tires Using ANSYS, Recent Advances in Industrial and Manufacturing Technologies, 2012

[15] Eswara Kumar A, Somanadha Sastry K, Manideep K, Priyanka M., Dynamic Analysis of Flex Seal of Solid Rocket Motor Nozzle, 5th International Conference of Materials Processing and Characterization (ICMPC 2016), 2017

[16] X.-G. Song, L. Wang, Y.-C. Park, Analysis and optimization of nitrile butadiene rubber sealing mechanism of ball valve. Transactions of Nonferrous Metals Society of China, 2009

[17] B. Pinedo, J. Aguirrebeitia, M. Conte, A. Igartua, Tri-dimensional eccentricity model of a rod lip seal. Tribology International, 2014 
[18] H. D Gurav, S.B.Sanap, B. Duggirala, Non-Linear Finite Element Analysis of Rubber Bush for 2Wheeler Rear Shock Absorber for Prediction of Fatigue Life, International Journal of Advance Research in Engineering, Science \& Technology(IJAREST), 2015

[19] V. Gangadhar, S. Babu, R. M. Cadambi, R. R. Rao, N. Venkataram, Design and Analysis of Rubber Pallet for Industrial Application, AMMMT 2016

[20] MSC.Software Corporation, Whitepaper - Nonlinear Finite Element Analysis of Elastomers, 2010

[21] MSC.Software Corporation, Technical Paper-Nonlinear Finite Element Analysis of elastomers, 2000

[22] N. Békési, K. Váradi, Wear simulation of a reciprocating seal by global remeshing, Periodica Polytechnica, 2010

[23] R. H. T. Ueda, L. C. Brandão, C. H. Lauro, Analysis of Automotive Liftgate Seals Using Finite Element Analysis, Polímeros, 2010

[24] Z. Wenfeng, W. Jie, L. Peijian, Numerical analysis and optimal design for new automotive door sealing with variable cross-section. Finite Elements Analysis and Design, 2014

[25] M. Spizzuoco, A. Calabrese, G. Serino, Innovative low-cost recycled rubber-fiber reinforced isolator: Experimental tests and Finite Element Analyses. Engineering Structures, 2014

[26] M. Ismail, J. Rodellar, G. Carusone, M. Domaneschi, L. Martinelli, Characterization, modeling and assessment of Roll-N-Cage isolator using the cable-stayed bridge benchmark, Acta Mech 224, 2013

[27] T. Mankovits, D. Huri, I. Kállai, I. Kocsis, T. Szabó, Material Characterization and Numerical Simulation of a Rubber Bumper, International Journal of Industrial and Manufacturing Engineering, 2014

[28] A. Vámosi, T. Mankovits, D. Huri, I. Kocsis, T. Szabó, Comparison of Different Data Acquisition Techniques for Shape Optimization Problems. International Journal of Mechanical, Aerospace, Industrial, Mechatronic and Manufacturing Engineering, 2015

[29] D. Bortoli, E. Wrubleski, R. J. Marczak, J. Gheller, Hyperfit - Curve Fitting Software For Incompressible Hyperelastic Material Models, Brazilian Congress of Mechanical Engineering, 2011

[30] V. Carlescu, G. Prisacaru, N. D. Olaru, FEM Simulation on Uniaxial Tension of Hyperelastic Elastomers, Applied Mechatronics and Materials, 2014

[31] M. Sasso, G. Palmieri, G. Chiappini, D. Amodio, Characterization of hyperelastic rubber-like materials by biaxial and uniaxial stretching tests based on optical methods. Polymer Testing, 2008

[32] Y. Gorash, T. Comlekci, R. Hamilton, CAE-based application for identification and verification of hyperelastic parameters, Journal of Materials: Design and Applications, 2017 
[33] P. Altidis, B. Warner, Analyzing Hyperelastic Materials/ Some Practical Considerations, Midwest ANSYS Users Group, 2005

[34] D. Felhõs, D. Xu, A. K. Schlarb, K. Váradi, T. Goda, Viscoelastic characterization of an EPDM rubber and finite element simulation of its dry rolling friction, eXPRESS Polymer Letters Vol.2, No.3, 2008

[35] S. Maas, D. Rawlins, J. Weiss, G. Ateshian, FEBio User's Manual version 2.4, 2015

[36] MSC.Software Corporation, Marc 2010 User's Guide

[37] ADINA R \& D, Inc., ADINA Theory and Modeling Guide, Volume I: ADINA Solids \& Structures, 2012

[38] FEMAP 9.3, Help\&User's Guide, 2009 